\title{
Social support of patients attending a geriatric day hospital
}

\author{
H. PEACH AND M. S. PATHY \\ From the Department of Geriatric Medicine, University Hospital of Wales, Cardiff
}

SUMMARY A longitudinal survey of the social support of patients attending one geriatric day hospital confirmed an impression that support was not being adjusted to meet the changing degrees of dependency among the patients. An experimental study, in which the social support available to a small group of consecutive new admissions was reduced, showed that their dependency scores were not significantly different from those of a control group which continued to receive support. The significance of this finding in reducing the cost of day hospital care is discussed.

Much has been written about the benefit elderly patients derive from day hospitals, but no study has shown whether this benefit is provided at the expense of an increase in the social support of the patients. Nor has any study confirmed that there is any associated reduction in the services such patients need, although such a result would clearly be advantageous.

Social service costs are a heavy item in the overall cost of day hospital care. In one of the few costings of geriatric day hospitals, Ross (1976) based the social service costs on data obtained from 50 patients attending during a typical week, but did not take account of the fact that patients were at different stages in their rehabilitation, nor of the change in the amount of social support needed by patients as they become more independent. Therefore, the social service costs may have been overestimated. A longitudinal survey of the social support of patients attending St. David's Geriatric Day Hospital, Cardiff, is reported in Part 1 of this paper, and an experimental study is described in Part 2 . In this, the social support available to a small group of consecutive new admissions was reduced, while a control group continued to be supported.

P A R T 1

\section{Methods}

Eighty patients attending St. David's Day Hospital for the first time were included in the survey. At the time of admission, we noted the patients' sex, age, type of residence, condition(s) leading to attendance, frequency of use of domiciliary services, and whether patients were visited 'regularly' by a general practitioner, neighbour, relative, or friend. The domiciliary services noted included meals-on-wheels, home help, community nurse, and health visitor. We also noted whether there was a 'carer', and if there was, whether he or she was the spouse, daughter, unmarried son, daughter-in-law, or other relative, and whether the 'carer' lived with the patient or was a neighbour.

One month after admission, we noted: whether patients had received physical therapy with the aim of improving or maintaining their level of independence; medical care (diagnostic and therapeutic services); nursing care (bathing; washing hair, help with meals, and help with the toilet); and social care. Help with collection of samples, application of dressings, and administering medication, was included under medical care. The domiciliary services being used by patients were again recorded.

The level of dependence was assessed on admission, and one month after admission, using a modified Barthel Index (Mahoney and Barthel, 1965) (Table 1). The changes in dependency scores were compared with the changes in the amount of social services used.

\section{Results}

Twenty-eight of the 80 patients were men and 52 were women. Fifty-two were over 75 years old (Table 2). Only 10 patients, all women, had no 'carer' (Table 3). For patients under the age of 70 , the 'carer' was often the spouse. In the older age groups, the 'carer' was often a daughter or daughterin-law. Among the seventy patients who had a 'carer', this person lived with 60 patients, and was a neighbour of 10 . Only 10 patients lived apart from their 'carers'. 
Table 1 Dependency rating scale

\begin{tabular}{|c|c|c|c|}
\hline Activity & With help & $\begin{array}{c}\text { SCORES } \\
\text { Independently } \\
\text { with difficulty }\end{array}$ & Independently \\
\hline $\begin{array}{l}\text { Feeding } \\
\text { Moving from bed to } \\
\text { chair and returning } \\
\text { (includes sitting up } \\
\text { in bed) } \\
\text { Personal toilet (wash } \\
\text { face and comb hair) } \\
\text { Bathing self } \\
\text { Getting on and off } \\
\text { wC (handling clothes, } \\
\text { wiping self, and } \\
\text { flushing wC) } \\
\text { Walking on } \\
\text { level surface } \\
\text { Propelling wheelchair } \\
\text { if unable to walk } \\
\text { Going up and } \\
\text { down stairs } \\
\text { Dressing }\end{array}$ & $\begin{array}{r}5 \\
10 \\
0 \\
5 \\
5\end{array}$ & $\begin{array}{r}10 \\
15 \\
5 \\
10 \\
10\end{array}$ & $\begin{array}{l}20 \\
10 \\
10 \\
15 \\
20 \\
10 \\
15 \\
15\end{array}$ \\
\hline
\end{tabular}

Table 2 Age and sex distribution of patients attending day hospital

\begin{tabular}{lcc}
\hline Age group (years) & Men & Women \\
\hline Under 65 & 2 & 2 \\
$65-69$ & 4 & 6 \\
$70-74$ & 8 & 6 \\
$75-79$ & 6 & 24 \\
$80-84$ & 2 & 10 \\
85 or over & 6 & 4 \\
All ages & 28 & 52 \\
\hline
\end{tabular}

Table 3 'Carers' of patients attending day hospital

\begin{tabular}{lcc}
\hline Status of 'carer' & Men & Women \\
\hline No 'carer' & 0 & 10 \\
Spouse & 14 & 12 \\
Daughter & 10 & 16 \\
Single son & 0 & 0 \\
Daughter-in-law & 4 & 14 \\
Other relative & 0 & 0 \\
Friend & 0 & 0 \\
All patients & 28 & 52 \\
\hline
\end{tabular}

Table 4 Numbers of patients using domiciliary services on admission to day hospital

\begin{tabular}{lll}
\hline Type of service & Men & Women \\
\hline Community nurse & 14 & 20 \\
Home help & 12 & 22 \\
Health visitor & 18 & 30 \\
Meals-on-wheels & 2 & 16 \\
\hline
\end{tabular}

Table 5 Sources of referral of patients to day hospital

\begin{tabular}{lcl}
\hline Source & Men & Women \\
\hline Health visitor & 6 & 16 \\
Inpatient ward & 15 & 13 \\
Outpatient clinic & 0 & 5 \\
GP & 5 & 10 \\
\hline
\end{tabular}

Table 6 Conditions leading to admission of patients to day hospital

\begin{tabular}{lcc}
\hline Condition & Men & Women \\
\hline Stroke & 8 & 11 \\
Chronic joint disease & 0 & 19 \\
Ischaemic heart disease & 7 & 4 \\
Chronic chest disease & 3 & 2 \\
Other conditions & 10 & 16 \\
All conditions & 28 & 52 \\
\hline
\end{tabular}

Table 7 Frequency of use of social services on admission to day hospital and one month afterwards

\begin{tabular}{|c|c|c|c|c|}
\hline \multirow{3}{*}{$\begin{array}{l}\text { Social service } \\
\text { Community nurse } \\
\text { Health visitor } \\
\text { Home help } \\
\text { Meals-on-wheels }\end{array}$} & \multicolumn{4}{|c|}{ Times per week (mean and range) } \\
\hline & \multicolumn{2}{|c|}{ On admission } & \multicolumn{2}{|c|}{ One month afterwards } \\
\hline & $\begin{array}{l}3 \cdot 0 \\
0 \cdot 4 \\
4 \cdot 9 \\
4 \cdot 9\end{array}$ & $\begin{array}{l}(0 \cdot 25-7) \\
(0 \cdot 25-1) \\
(1-7) \\
(3-7)\end{array}$ & $\begin{array}{l}2 \cdot 2 \\
0 \cdot 4 \\
4 \cdot 9 \\
4 \cdot 2\end{array}$ & $\begin{array}{l}(0 \cdot 25-10) \\
(0 \cdot 25-1) \\
(1-7) \\
(3-6)\end{array}$ \\
\hline
\end{tabular}

Thirty-four patients in the sample of 80 lived in their own houses, 18 in council houses, six in their own flats, and 22 in council flats.

Thirty-four patients had a community nurse; the proportion tended to decrease in the older age groups (Table 4). Thirty-four patients had a home help, but the proportion did not differ significantly between age groups. Eighteen patients, mainly women, had meals-on-wheels, and the proportion tended to increase in older age groups. Forty-eight patients had a health visitor, including all the 14 patients under the age of 70 , but the proportions did not differ significantly between older age groups.

Health visitors referred 22 of the patients to the day hospital (Table 5). Thirty-eight of the total number of referrals were due to strokes and chronic joint disease (Table 6).

Table 7 shows the frequency of use of the different social services. The frequencies did not differ significantly with sex or age. Thirteen patients were visited 'regularly' by their GPs, and 60 by a neighbour, relative, or friend.

During the month after the patients were admitted to the day hospital, the medical staff adjusted their attendance according to the progress they made (assessed on purely clinical grounds). There was no change in the social circumstances of any of the patients that made it necessary for them to attend the day hospital more, or less, frequently. On admission, the mean attendance was 1.8 times a week, with a range of one to 5 times a week. At the end of the month, the mean attendance was 1.6 times a week, with a range of one to 5 times a week.

ONE MONTH AFTER ADMISSION

Forty-four patients were given physical therapy intended to rehabilitate them (Table 8). The propor-

Table 8 Numbers of male and female patients using hospital services of various kinds

\begin{tabular}{lcc}
\hline Service & Men & Women \\
\hline Rehabilitation & 20 & 24 \\
Physical maintenance & 6 & 30 \\
Social care & 14 & 26 \\
Help with meals and/or toilet & 10 & 26 \\
Help with washing hair and/or bathing & 10 & 26 \\
Medical care & 8 & 8 \\
\hline
\end{tabular}


tion did not differ significantly between age groups and was the same as the proportion of patients with locomotor disorders in each age group. Thirtysix patients received physical therapy aimed at maintaining their independence; the proportion tended to increase in the older age groups. All patients received medical care. Thirty-six needed help with washing their hair or having a bath, or both, the proportion tending to be higher in younger age groups. In these age groups, the 'carer' tended to be a spouse, who, being the same age as the patient, was physically incapable of helping with these activities. In the older age groups, the 'carer' tended to be a daughter or daughter-in-law, who was younger and fitter, and able to cope with washing hair and bathing once a week. Thirty-six patients needed help with meals or with using the WC, and the proportion did not differ significantly between age groups. Forty patients were referred partly for social care, and the proportion did not differ significantly between age groups. The most common reason for referral was the inability of the 'carer' to cope.

Attendance at the day hospital resulted in a reduction in the frequency with which patients received meals-on-wheels, but the frequency of their use of a home help or a health visitor was unchanged (Table 7). The same number of patients were still visited by a community nurse, but less frequently.

The mean dependency scores did not differ significantly with age or sex (Table 9). There was no correlation between a patient's dependency score

Table 9 Dependency scores of patients on admission to day hospital

\begin{tabular}{lll}
\hline Age group (years) & Men & Women \\
\hline Under 65 & 92 & 97 \\
$65-69$ & 90 & 96 \\
$70-74$ & 91 & 98 \\
$75-79$ & 93 & 97 \\
$80-84$ & 91 & 98 \\
85 or over & 85 & 91 \\
\hline
\end{tabular}

and the number of domiciliary services he or she used. The dependency scores of $\mathbf{4 0}$ patients significantly improved, those of 38 patients remained static, and those of two patients deteriorated.

\section{PART 2}

\section{Methods}

The experimental study covered twenty-two patients admitted consecutively to the day hospital. They were receiving home help or meals-on-wheels, or both, and had a dependency score of at least 75. They had to be able to perform most activities, except bathing, at least 'independently with difficulty'. Sixteen were women and six were men.

Twenty of the patients were aged 70 or over. Fourteen had a 'carer', in four cases the spouse, and in 10 cases a daughter or daughter-in-law. The 'carer' lived with, or was a neighbour of, 12 patients. An equal number of patients lived in houses and flats. All patients had a home-help, 12 had meals-onwheels, eight had a community nurse, and 18 had a health visitor. Ten patients were referred because of a stroke or chronic joint disease. Ten patients received physical therapy with the aim of rehabilitating them, and six received physical therapy with the aim of maintaining their independence. Twelve patients were referred partly on social grounds: either there was no chief 'carer' or the chief 'carer' could not cope with the patient's demands. Ten patients needed help with meals or using the WC, or both, and 14 needed help with washing hair or bathing, or both. The mean dependency score was $\mathbf{9 9 . 2}$ with a range from $\mathbf{7 5}$ to 125 .

They were matched with 22 patients in a control group for age, existence of a 'carer', social services used, presence of a locomotor disorder, and dependency score.

The home help and meals-on-wheels were discontinued for all patients in the experimental study group on first attendance at the day hospital. Their dependency scores were re-assessed one month after admission to the day hospital, and compared with those of the control group.

\section{Results}

The mean dependency scores of the 22 patients who had their social support reduced was $108 \cdot 8$ (range 85 to 130 ) and did not differ significantly from that of the control group 109.6 (range 85 to 130).

\section{Discussion}

Apart from a reduction in the frequency with which some patients received meals-on-wheels, because of their attendance at the day hospital, the amount of social support the patients received was not adjusted when they first attended the hospital. The medical staff considered that the patients were receiving the correct amount of social support, but the medical assessment on admission, consisting of the traditional history and examination, does not give a very reliable picture of the amount of social support patients need. Because of pressure of numbers, only selected patients were able to have a formal assessment by an occupational therapist of their 
ability to perform the ordinary tasks of daily life. The empirical nature of decisions about how much support patients need was emphasised by the lack of correlation between amount of social support and dependency score.

If day hospitals are to function effectively, there should be a reduction in the amount of social services used by patients as they become more independent. It can be argued that the elderly may have come to rely on the domiciliary services, and that a reduction could affect their ability to remain independent. However, the group for whom some domicilary services were discontinued had a dependency score which was not significantly lower than that of the group which continued to be supported.
This survey emphasises the need to relate provision of domiciliary services to changes in a patient's dependency. A possible way of reducing the overall cost of day hospitals is also apparent.

Reprints from H. Peach, Department of Geriatric Medicine, University Hospital of Wales, Cardiff.

\section{References}

Mahoney, F. L., and Barthel, D. W. (1965). Functional Evaluation: the Barthel Index. Maryland Medical Journal, 14, 61.

Ross, D. N. (1976). Geriatric day hospitals: counting the cost compared with other methods of support. Age and Ageing, 5, 171. 